\title{
Differential Effects of Scopolamine on Memory Processes in the Object Recognition Test and the Morris Water Maze Test in Mice
}

\author{
Dong Hyun $\mathrm{KIm}^{1,3}$ and Jong Hoon Ryu $\mathrm{u}^{1,2,3 *}$ \\ ${ }^{1}$ Department of Life and Nanopharmaceutical Sciences, ${ }^{2}$ Oriental Pharmaceutical Science and \\ ${ }^{3}$ Kyung Hee East-West Pharmaceutical Research Institute, College of Pharmacy, \\ Kyung Hee University, Hoeki-dong, Dongdaemoon-Ku, Seoul 130-701, Korea
}

(Received May 14, 2008; Revised July 11, 2008; Accepted July 13, 2008)

\begin{abstract}
Several lines of evidence indicate that scopolamine as a nonselective muscarinic antagonist disrupts object recognition performance and spatial working memory when administered systemically. In the present study, we investigated the different effects of scopolamine on acquisition, consolidation, and retrieval phases of object recognition performance and spatial working memory using the object recognition and the Morris water maze tasks in mice. In the acquisition phase test, scopolamine decreased recognition index on object recognition task and the trial 1 to trial 2 differences on Morris water maze task. In the consolidation and retrieval phase tests, scopolamine also decreased recognition index on object recognition task, where as scopolamine did not exhibited any effects on the Morris water maze task.
\end{abstract}

Keywords: Scopolamine, Object recognition test, Morris water maze, Acquisition, Consolidation, Retrieval

\section{INTRODUCTION}

There are three stages for learning and memory processing including acquisition, consolidation, and retrieval processes (Abel and Lattal, 2001). After detection by the sensory system, information is rapidly encoded and may pass into labile memory. During consolidation, this memory may then be consolidated into long-term storage. The retrieval process is the final stage which uses the consolidated and more fixed memory. It is important to know the effects of a compound on each stage of memory processing as the compound which improves multiple cognitive processes will be most useful as a treatment for memory deficits (Prickaerts et al., 2005). However, it is difficult to differentiate each stage of memory processing experimentally because two or more stages of memory are affected by experimental techniques, depending on the time course of the manipulations and the neurotransmitter system(s) involved (Collinson et al., 2006).

One of the most common pharmacological models used to test cognitive enhancer efficacy is scopolamineinduced memory deficits. This model has been used for

\footnotetext{
${ }^{*}$ Corresponding author

Tel: $+82-2-961-9230, \quad$ Fax: $+82-2-966-3885$

E-mail: jhryu63@khu.ac.kr
}

development or pharmacological assessment of antiamnesic drugs for several years and has been extensively studied with a variety of tasks, such as passive avoidance, the Y-maze, the Morris water maze, and object recognition (Vannucchi et al., 1997). To clarify the utility of this model to predict therapeutic efficacy of cognitive enhancers, it is critical to understand which types of memory (e.g. spatial vs. non spatial) and stages of processing (e.g. acquisition, consolidation, and retrieval) are (and are not) sensitive to scopolamine-induced disruption.

Several lines of evidences suggest that excitotoxic cellbody lesions of perirhinal (PRh) cortex do not affect the performance of spatial learning and memory tasks that depend on intact hippocampal functioning (Bussey et al., 1999). Memory performance in the object recognition task, however, is severely affected by this lesion (Norman and Eacott, 2004). These results suggest that at least in part, different neural mechanisms underlie spatial memory and visual recognition memory. The Morris water maze task is used to assess hippocampal-dependent spatial learning (Molchan et al., 1992), whereas the object recognition task is mainly dependent on the PRh cortex (Mumby and Pinel, 1994). To accurately compare the effects of cholinergic blockade on the 3 phases of memory processing across object recognition and spatial memory, we have developed an identical time schedule 
for scopolamine treatment at all 3 phases in each task. This study will thus provide valuable information on the effects of scopolamine treatment on the entirety of the memory formation process.

\section{MATERIALS AND METHODS}

\section{Animals}

Male ICR mice weighing 25-30 g were obtained from the Orient Co., Ltd., a branch of Charles River Laboratories (Seoul). All animal procedures were conducted in accordance with the Principle of Laboratory Animal Care (NIH publication No. 85-23, revised 1985) and the Animal Care and the Use Guidelines of Kyung Hee University, Korea. Mice were housed 5 per cage in a housing room maintained at a constant temperature $\left(23 \pm 1^{\circ} \mathrm{C}\right)$ and humidity $(60 \pm 10 \%)$, and under a 12-h light/ dark cycle (light on 07.30-19.30 h). Food and water were available ad libitum at all times except during testing. All behavioral tasks were conducted between 10:00 $\mathrm{h}$ and 16:00 $\mathrm{h}$.

\section{Morris water maze task}

The Morris water maze task was carried out as described elsewhere (Kim et al., 2007). On the following day, acquisition and retrieval session were conducted (Fig. 1). During the acquisition session, the mice were given four trials with the platform in place. When a mouse located the platform, it was permitted to remain on it for $10 \mathrm{~s}$ and was then placed in a holding cage for $30 \mathrm{~s}$ (ITI) until the start of the next trial. If the mouse did not locate the platform within $60 \mathrm{~s}$, it was placed on the platform for $10 \mathrm{~s}$. At the end of the ITI, the mouse was again placed into the pool but at a different location; and upon release, the next trial began. This procedure was repeated until

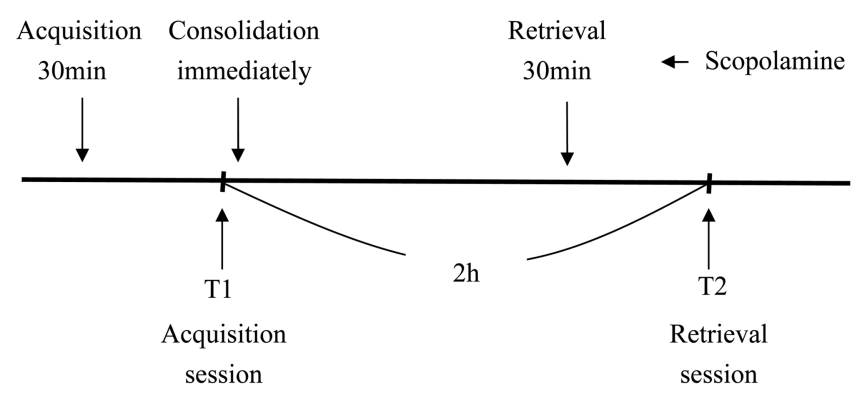

Fig. 1. Study design schematic. Scopolamine was administered 30 min before the acquisition phase for acquisition memory, immediately after the acquisition phase for consolidation memory, or 30 min before retrieval testing for retrieval memory. The $2 \mathrm{~h}$ period was used between acquisition session (T1) and retrieval session (T2) both in the Morris water maze task and in object recognition task. four trials had been completed. Retrieval session was conducted $2 \mathrm{~h}$ after the fourth trial of acquisition session. During the retrieval session, the mice were given one trial with the platform. The improvement in the animal's memory was calculated by subtracting the latency to find the platform during the retrieval trial from the mean latency to find the platform for all 4 acquisition trials to give the savings score (Collinson et al., 2006). The following measurements were taken and analyzed using the videobased Ethovision System: escape time and swimming speed in the Morris water maze test.

Mice received injections of either vehicle (normal saline, i.p.) or scopolamine $(0.25,0.5,1$, or $2 \mathrm{mg} / \mathrm{kg}$, i.p.) $30 \mathrm{~min}$ before the first trial of acquisition session, immediately after acquisition session, or 30 min before retrieval session to examine its effects on acquisition, consolidation and retrieval, respectively.

\section{Object recognition test}

The object recognition task was carried out as described elsewhere (Bertaina-Anglade et al., 2006). On experimental day, animals were subjected to two sessions and each session was composed of one trial. During first session (acquisition trial, trial 1), animals were placed in the arena containing two identical objects for 5 minutes (Fig. 1). Any mice not exploring the objects for $20 \mathrm{~s}$ within the $5 \mathrm{~min}$ period were excluded from experiments. Exploration is defined as the animal directing its nose within $1 \mathrm{~cm}$ of the object while looking at, sniffing, or touching it. For the second session (retrieval session, trial 2 ), $2 \mathrm{~h}$ after trial 1 , one of the objects presented in the first trial was replaced by an unknown object (novel object), animals were placed back in the arena for $5 \mathrm{~min}$ and total time spent in exploration of each object and locomotor activities were determined (Fig. 1). The following parameters were measured using the video-based Ethovision System: locomotor activity and time spent in active exploration of the familiar $(F)$ or novel $(N)$ object on trial 2. Recognition memory was evaluated using a recognition index $(\mathrm{RI})$ calculated for each animal using the formula: $[(N-F) /(N+F)] \times 100$ corresponding to the difference between the time exploring the novel and the familiar object, corrected for total time exploring both objects (Ennaceur and Delacour, 1988).

Mice received vehicle (normal saline, i.p.) or scopolamine $(0.25,0.5,1$, or $2 \mathrm{mg} / \mathrm{kg}$, i.p.) $30 \mathrm{~min}$ before trial 1 , immediately after trial 1 , or 30 min before trial 2 to examine its effects on acquisition, consolidation and retrieval, respectively. (-) Scopolamine hydrobromide was purchased from the Sigma Chemical Co. (USA). 


\section{Statistics}

Values are expressed as means \pm S.E.M. For the object recognition and Morris water maze tests, data were analyzed by one-way analysis of variance (ANOVA) followed by the Student-Newman-Keuls test for multiple comparisons. Statistical significance was set at $P<0.05$.

\section{RESULTS}

\section{Effect of scopolamine on the Morris water maze task}

Analysis of swimming speed during the retrieval session did not show any significant differences among each experimental group in acquisition $[F(4,45)=0.13, P=0.97]$, consolidation $[F(4,45)=0.94, P=0.45]$, or retrieval $[F(4$, $45)=0.77, P=0.55]$ phases (Table I). There was a significant group effect of treatment on the savings between acquisition session and retrieval session $[F(4,45)=4.83$, $P=0.003$ ] with Student-Newman-Keuls test, showing that the mean savings of the scopolamine treated groups (1

Table I. Swimming speed of the mice during retention session in the Morris water maze task

\begin{tabular}{lll}
\hline & & $\begin{array}{c}\text { Swimming speed } \\
\text { (cm/s) }\end{array}$ \\
\hline Acquisition phase & & $34.8 \pm 2.6$ \\
Control & & $34.9 \pm 3.6$ \\
Scopolamine & $0.25 \mathrm{mg} / \mathrm{kg}$ & $35.1 \pm 1.7$ \\
& $0.5 \mathrm{mg} / \mathrm{kg}$ & $35.6 \pm 1.5$ \\
& $1 \mathrm{mg} / \mathrm{kg}$ & $33.3 \pm 1.6$ \\
& $2 \mathrm{mg} / \mathrm{kg}$ & \\
Consolidation phase & & $36.8 \pm 3.6$ \\
Control & & $32.9 \pm 3.4$ \\
Scopolamine & $0.25 \mathrm{mg} / \mathrm{kg}$ & $36.1 \pm 1.7$ \\
& $0.5 \mathrm{mg} / \mathrm{kg}$ & $38.5 \pm 2.5$ \\
& $1 \mathrm{mg} / \mathrm{kg}$ & $38.3 \pm 3.6$ \\
& $2 \mathrm{mg} / \mathrm{kg}$ & \\
Retrieval phase & & $41.9 \pm 2.1$ \\
Control & & $40.9 \pm 2.1$ \\
Scopolamine & $0.25 \mathrm{mg} / \mathrm{kg}$ & $38.8 \pm 2.4$ \\
& $0.5 \mathrm{mg} / \mathrm{kg}$ & $36.6 \pm 3.4$ \\
& $1 \mathrm{mg} / \mathrm{kg}$ & $39.6 \pm 1.1$ \\
\hline
\end{tabular}

Control group received vehicle solution (saline, i.p.) and scopolamine-treated group was administered with scopolamine by each dose (i.p.). Data are expressed as mean \pm S.E.M. $n=$ 10/group. and $2 \mathrm{mg} / \mathrm{kg}$ ) was significantly lower than those of the control group in the acquisition phase (Fig. 2A). How-
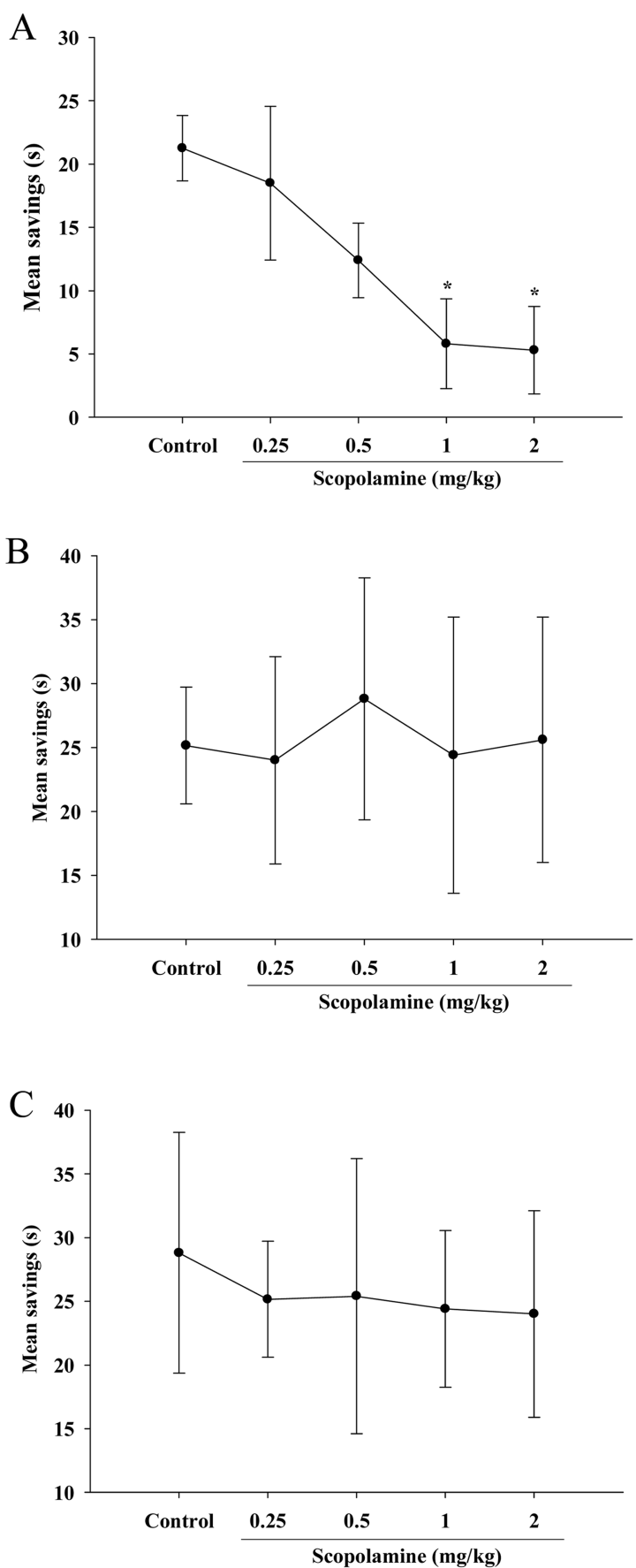

Fig. 2. Effect of scopolamine on acquisition (A), consolidation $(B)$, and retrieval $(C)$ phases of the Morris water maze. Each memory phase was evaluated as described in Materials and Methods. The effects of scopolamine on the mean savings (i.e. the increased ability to find the platform in retrieval session) were expressed. Data represent means \pm S.E.M of $n=10 /$ group ( ${ }^{\star} P<0.05$ versus vehicle control group). 
Table II. The total exploration time spent both objects and locomotor activities of the mice in T2 on the object recognition task

\begin{tabular}{llcc}
\hline & & $\begin{array}{c}\text { Total exploration } \\
\text { time }(\mathrm{s})\end{array}$ & $\begin{array}{c}\text { Locomotor } \\
\text { activity }(\mathrm{cm})\end{array}$ \\
\hline $\begin{array}{l}\text { Acquisition phase } \\
\text { Control }\end{array}$ & $35.82 \pm 8.48$ & $2319.44 \pm 412.39$ \\
Scopolamine & $0.25 \mathrm{mg} / \mathrm{kg}$ & $34.99 \pm 6.64$ & $2892.64 \pm 197.45$ \\
& $0.5 \mathrm{mg} / \mathrm{kg}$ & $35.05 \pm 5.89$ & $2672.18 \pm 238.33$ \\
& $1 \mathrm{mg} / \mathrm{kg}$ & $38.57 \pm 7.63$ & $2334.69 \pm 195.83$ \\
& $2 \mathrm{mg} / \mathrm{kg}$ & $34.16 \pm 6.82$ & $2434.69 \pm 211.83$ \\
Consolidation phase & & \\
Control & & $20.70 \pm 2.44$ & $2439.89 \pm 197.97$ \\
Scopolamine & $0.25 \mathrm{mg} / \mathrm{kg}$ & $22.40 \pm 2.33$ & $2434.69 \pm 195.83$ \\
& $0.5 \mathrm{mg} / \mathrm{kg}$ & $21.70 \pm 1.99$ & $2334.69 \pm 195.83$ \\
& $1 \mathrm{mg} / \mathrm{kg}$ & $23.50 \pm 1.34$ & $2892.64 \pm 492.93$ \\
& $2 \mathrm{mg} / \mathrm{kg}$ & $20.40 \pm 2.33$ & $2672.18 \pm 258.19$ \\
Retrieval phase & & & \\
Control & & $21.20 \pm 2.52$ & $2639.74 \pm 492.53$ \\
Scopolamine & $0.25 \mathrm{mg} / \mathrm{kg}$ & $22.50 \pm 2.30$ & $2892.64 \pm 197.45$ \\
& $0.5 \mathrm{mg} / \mathrm{kg}$ & $22.10 \pm 1.98$ & $2634.52 \pm 195.83$ \\
& $1 \mathrm{mg} / \mathrm{kg}$ & $23.80 \pm 1.94$ & $2672.18 \pm 258.42$ \\
& $2 \mathrm{mg} / \mathrm{kg}$ & $18.80 \pm 2.38$ & $2534.69 \pm 195.66$ \\
\hline
\end{tabular}

Control group received vehicle solution (saline, i.p.) and scopolamine-treated group was administered with scopolamine by each dose (i.p.). Data are expressed as mean \pm S.E.M. $n=$ 10/group.

ever, scopolamine did not affects the savings in the consolidation $[F(4,45)=0.05, P=0.98]$ and retrieval phases $[F(4,45)=0.05, P=0.99]$ (Figs. $2 \mathrm{~B}$ and $2 \mathrm{C}$ ).

\section{Effect of scopolamine on the object recognition task}

Analysis of total exploration times and locomotor activity during $\mathrm{T} 2$ did not show any differences across each experimental group in acquisition $([F(4,45)=0.20, P=0.94]$; $[F(4,45)=0.78, P=0.54])$, consolidation $([F(4,45)=0.36$, $P=0.84]$; $[F(4,45)=0.76, P=0.55])$, or retrieval $([F(4,45)$ $=0.70, P=0.60] ;[F(4,45)=0.53, P=0.71])$ phases tested (Table II). There were significant group effects of treatment on the acquisition $[F(4,45)=7.51, P<0.001]$, consolidation $[F(4,45)=5.23, P=0.002]$, and retrieval $[F(4$, $45)=8.94, P<0.001]$ phases with Student-Newman-Keuls test, showing that at $0.5-2 \mathrm{mg} / \mathrm{kg}$ of scopolamine treatment the recognition index was significantly lower compared to vehicle treatment (Fig. 3). As shown in Fig. 3, recognition indices were significantly decreased over 0.5
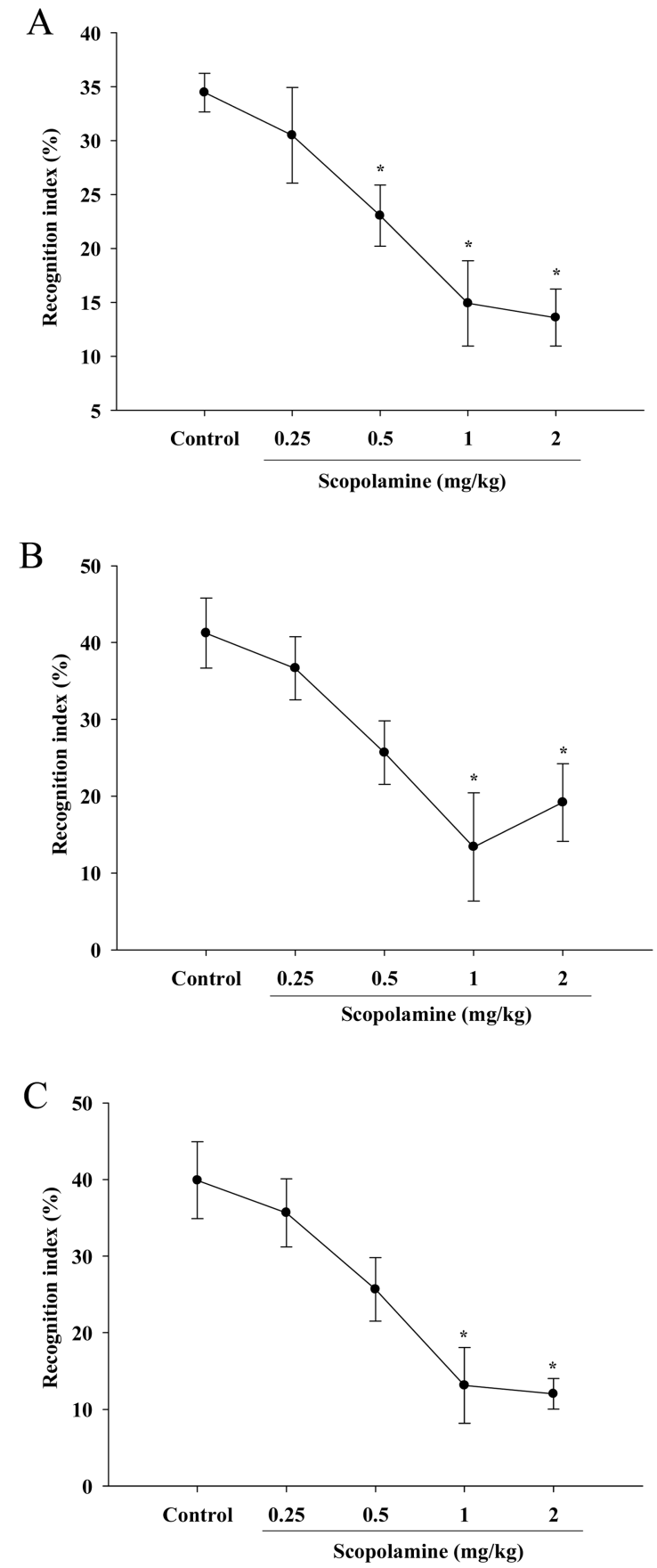

Fig. 3. Effect of scopolamine on acquisition (A), consolidation $(B)$, and retrieval $(C)$ phases of the object recognition test. Each memory phase was evaluated as described in Materials and Methods. The effects of scopolamine on the recognition index $[(N-F / N+F) \times 100]$ were expressed. Data represent means \pm S.E.M of $n=10$ /group ( ${ }^{*} P<0.05$ versus vehicle control group).

$\mathrm{mg} / \mathrm{kg}$ in the acquisition phase (Fig. 3A) and over $1 \mathrm{mg} /$ $\mathrm{kg}$ in the consolidation (Fig. 3B) and retrieval phases (Fig. 3C) and those were dose-dependent. 


\section{DISCUSSION}

In the present study, we tested the hypothesis that scopolamine would have differential effects on memory stages across the object recognition and morris water maze task. In order to compare those effects in two different tasks, we modulated these tasks with the same time schedule (see Fig. 1). Systemic administration of scopolamine impaired the acquisition phase of memory but not the consolidation and retrieval phases on the Morris water maze task. Conversely, scopolamine impaired acquisition, consolidation, and retrieval phases in a dose dependent manner in object recognition task.

It is generally accepted that hippocampal cholinergic system plays an important role in various cognitive functions including spatial working memory (Everitt BJ, Robbins, 1997). Spatial working memory deficits were severely affected by systemic injections or dorsal hippocampal infusion of scopolamine (Riekkinen et al., 1990; Whishaw, 1985). Riekkinen and Riekkinen (1997) reported that scopolamine impaired only acquisition, but had no effect on consolidation and retrieval in the water maze paradigm, suggesting that activation of muscarinic receptors in the hippocampal formation is needed only during the acquisition stage. Others also reported similar results (Riekkinen et al., 1990; Whishaw, 1985). In agreement with those published data, we also observed that administration of scopolamine $30 \mathrm{~min}$ before acquisition impaired spatial memory in the Morris water maze task. The administration of scopolamine immediately after acquisition session or 30 min before the retrieval session, however, had no effect on Morris water maze performance. Taken together, these results indicate that cholinergic neurotransmission plays an important role in the acquisition phase but not in the consolidation or retrieval phases of spatial working memory in the Morris water maze system. The sequence of molecular mechanisms underlying long-term potentiation (LTP) has been proposed to underlie memory consolidation (Malenka, 2003). LTP, a longlasting enhancement of synaptic transmission, was first reported in anesthetized and behaving animals (Bliss and Gardner-Medwin, 1973). LTP is believed to be a type of synaptic plasticity that underlies learning and memory. Muscarinic blockade or lesion of cholinergic neurons was reported not to affect hippocampal LTP (Jouvenceau et al., 1996). These mechanisms can explain that scopolamine has no effect on memory consolidation on hippocampal dependant spatial working memory.

The object recognition task is considered as a model of short-term episodic memory, initially described by Enna- ceur and Delacour (1988). Several studies indicate that pre-acquisition administration of scopolamine disrupts object recognition memory (Massey et al., 2003). Our results during the acquisition phase accorded with those previous results of a dose dependent effect of scopolamine treatment on novel object acquisition. Warburton et al. (2003) reported that the familiarity discrimination was impaired by scopolamine administration before acquisition but not after acquisition. It was also reported that scopolamine decreased the difference in the time spent exploring novel and familiar objects either by administration $15 \mathrm{~min}$ before or by administration immediately after exposure to objects, suggesting scopolamine deteriorates acquisition and consolidation phases (Norman et al., 2002). Consistent with the previous report, we also observed that scopolamine impaired those memory phases, although the doses and the time points used are slightly different. Indeed, it appears that at very long retention intervals (> $20 \mathrm{~h}$ ), scopolamine may enhance object recognition, which may be due to blockade of subsequent proactive interference from new memories stored after the object recognition acquisition phase. This treatment schedule is rarely used in tests of cognitive enhancers to reverse scopolamine induced deficits, however, and thus this effect of scopolamine is likely less relevant to the model's most common application.

There is strong evidence that the object recognition task is dependent on the integrity not of the hippocampus but of the PRh cortex which occupies the posterior portion of the rhinal sulcus in the rat (Ennaceur et al., 1996). Moreover, it is reported that PRh cortical neurons respond differentially to novel objects or pictures compared to familiar items, but not to novel arrangements of familiar objects (Wan et al., 1999). In the present study, we observed that memory consolidation and retrieval were impaired by the treatment of scopolamine in the object recognition task but in the Morris water maze task. These results suggest that consolidation and retrieval of object memory requires cholinergic neurotransmission. However, the role of other neural substrates cannot be excluded because the hippocampal formation is involved in the storage of long-term memory and may be involved in object recognition at long retention intervals (Hammond et al., 2004). Taken together, the object recognition task is a more sensitive task than the Morris water maze to cholinergic modulation across multiple phases of memory processing, and hence may be more useful for assessing the efficacy of putative cognitive enhancers that modulate the cholinergic system.

In conclusion, our results show that blockade of mus- 
carinic receptor with scopolamine affects the memory acquisition but not consolidation and retrieval of spatial memory. Conversely, scopolamine treatment impairs the acquisition, consolidation, and retrieval phases of object recognition. These results suggest that cholinergic neurotransmitter system differently affects spatial memory and object recognition memory on different memory phases.

\section{ACKNOWLEDGEMENTS}

This work was supported by a grant from Seoul Research and Business Development Program (10524). We thank Dr. Mark A. Geyer and Dr. Victoria B. Risbrough at University of California, San Diego for their helpful discussions and editorial assistance.

\section{REFERENCES}

Abel, T. and Lattal, K. M. (2001). Molecular mechanisms of memory acquisition, consolidation and retrieval. Curr. Opin. Neurobiol. 11, 180-187.

Bertaina-Anglade, V., Enjuanes, E., Morillon, D. and Drieu la Rochelle, C. (2006). The object recognition task in rats and mice: a simple and rapid model in safety pharmacology to detect amnesic properties of a new chemical entity. J. Pharmacol. Toxicol. Methods. 54, 99-105.

Bliss, T. V. and Gardner-Medwin, A. R. (1973). Long-lasting potentiation of synaptic transmission in the dentate area of the unanaestetized rabbit following stimulation of the perforant path. J. Physiol. 232, 357-374.

Bussey, T. J., Muir, J. L. and Aggleton, J. P. (1999). Functionally dissociating aspects of event memory: the effects of combined perirhinal and postrhinal cortex lesions on object and place memory in the rat. J. Neurosci. 19, 495-502.

Collinson, N., Atack, J. R., Laughton, P., Dawson, G. R. and Stephens, D. N. (2006). An inverse agonist selective for á5 subunit-containing $\mathrm{GABA}_{\mathrm{A}}$ receptors improves encoding and recall but not consolidation in the Morris water maze. Psychopharmacology (Berl). 188, 619-628.

Ennaceur, A. and Delacour, J. (1988). A new one-trial test for neurobiological studies of memory in rats: I. Behavioral data. Behav. Brain. Res. 31, 47-59.

Ennaceur, A., Neave, N. and Aggleton, J. P. (1996). Spontaneous object recognition and object location memory in rats: the effects of lesions in the cingulate cortices, the medial prefrontal cortex, the cingulum bundle and the fornix. Exp. Brain. Res. 113, 509-519.

Everitt, B. J. and Robbins, T. W. (1997). Central cholinergic systems and cognition. Annu. Rev. Psychol. 48, 649-684.

Hammond, R. S., Tull, L. E. and Stackman, R. W. (2004). On the delay-dependent involvement of the hippocampus in object recognition memory. Neurobiol. Learn. Mem. 82, 2634.

Jouvenceau, A., Billard, J. M., Lamour, Y. and Dutar, P. (1996).
Persistence of CA1 hippocampal LTP after selective cholinergic denervation. Neuroreport 7, 948-52.

Kim, D. H., Yoon, B. H., Kim, Y. W., Lee, S., Shin, B. Y., Jung, J. W., Kim, H. J., Lee, Y. S., Choi, J. S., Kim, S. Y., Lee, K. T., Ryu, J. H. (2007). The seed extract of Cassia obtusifolia ameliorates learning and memory impairments induced by scopolamine or transient cerebral hypoperfusion in mice. $J$. Pharmacol. Sci. 105, 82-93.

Malenka, R. C. (2003). The long-term potential of LTP. Nat. Rev. Neurosci. 4, 923-926.

Massey, P. V., Warburton, E. C., Wynick, D., Brown, M. W. and Bashir, Z. I. (2003). Galanin regulates spatial memory but not visual recognition memory or synaptic plasticity in perirhinal cortex. Neuropharmacology 44, 40-48.

Molchan, S. E., Martinez, R. A., Hill, J. L., Weingartner, H. J., Thompson, K., Vitiello, B. and Sunderland, T. (1992). Increased cognitive sensitivity to scopolamine with age and a perspective on the scopolamine model. Brain Res. Rev. 17, 215-226.

Mumby, D. G and Pinel, J. P. (1994). Rhinal cortex lesions and object recognition in rats. Behav. Neurosci. 108, 11-8.

Norman, G., Brooks, S. P., Hennebry, G. M., Eacott, M. J. and Little, H. J. (2002). Nimodipine prevents scopolamine-induced impairments in object recognition. J. Psychopharmacol. 16, 153-161.

Norman, G. and Eacott, M. J. (2004). Impaired object recognition with increasing levels of feature ambiguity in rats with perirhinal cortex lesions. Behav. Brain. Res. 148, 79-91.

Prickaerts, J., Sik, A., van der Staay, F. J., de Vente, J. and Blokland, A. (2005). Dissociable effects of acetylcholinesterase inhibitors and phosphodiesterase type 5 inhibitors on object recognition memory: acquisition versus consolidation. Psychopharmacology (Berl) 177, 381-390.

Riekkinen, M. and Riekkinen, P. Jr. (1997). Dorsal hippocampal muscarinic acetylcholine and NMDA receptors disrupt water maze navigation. Neuroreport 8, 645-648.

Riekkinen, P. Jr., Sirvio, J., Aaltonen, M. and Riekkinen, P. Effects of concurrent manipulations of nicotinic and muscarinic receptors on spatial and passive avoidance learning. Pharmacol. Biochem. Behav. 37, 405-410.

Vannucchi, M. G., Scali, C., Kopf, S. R., Pepeu, G. and Casamenti, F. (1997). Selective muscarinic antagonists differentially affect in vivo acetylcholine release and memory performances of young and aged rats. Neuroscience 79, 837846.

Wan, H., Aggleton, J. P. and Brown, M. W. (1999). Different contributions of the hippocampus and perirhinal cortex to recognition memory. J. Neurosci. 19, 1142-1148.

Warburton, E. C., Koder, T., Cho, K., Massey, P. V., Duguid, G., Barker, G. R. Aggleton, J. P., Bashir, Z. I. and Brown, M. W. (2003). Cholinergic neurotransmission is essential for perirhinal cortical plasticity and recognition memory. Neuron 38, 987-996.

Whishaw, I. Q. (1985). Formation of a place learning-set by the rat: a new paradigm for neurobehavioral studies. Physiol. Behav. 35, 139-143. 